\title{
The Influence of Diglossia on Different Types of Phonological Abilities in Arabic
}

\author{
Ibrahim A. Asadi ${ }^{1,2,3} \&$ Raphiq Ibrahim ${ }^{1,2}$ \\ ${ }^{1}$ The Department for Learning Disabilities, University of Haifa, Israel \\ 2 \\ ${ }^{2}$ The Edmond J. Safra Brain Research Center for the Study of Learning Disabilities, University of Haifa, Israel \\ ${ }^{3}$ The Cognitive Laboratory for Reading and Learning Research, Sakhnin College for Teachers' Education, \\ Sakhnin, Israel \\ Correspondence: Raphiq Ibrahim, Department of Learning Disabilities, University of Haifa, Mount Carmel, \\ Haifa 31905, Israel. E-mail: raphiq@psy.haifa.ac.il
}

Received: May 20, 2014

doi:10.5539/jel.v3n3p45
Accepted: June 23, $2014 \quad$ Online Published: July 17, 2014

URL: http://dx.doi.org/10.5539/jel.v3n3p45

\begin{abstract}
The present study examined the impact of diglossia, a characteristic of the Arabic language, on the development of phonological abilities in the spoken and the literary language forms. Participants were 571 children from 10 grade levels (1-7, 9, 11 and 12), which were recruited from 10 schools by taking into account two important factors: the accent factor (Bedouins, Druze and Arabs) and the geographical factor (south, Haifa, center and north). All participant were administered phonemic segmentation and phonemic deletion tasks, each comprised of two types of stimulus: spoken and literary words. The results indicated an opposite effects of the stimulus where in the phonemic segmentation tasks, an advantage was found for the spoken stimulus over the literary and in the phonemic deletion task, the advantage was recorded in the literary stimulus. In addition, a significant main effect of grade was found for both tasks. An interaction between grade and the type of stimulus was observed only in the phonemic deletion task. These differences between the two tasks may suggest that they are processed differently via the auditory and the visual modality. In addition, our findings provide evidence concerns the developmental capacity of phonemic awareness. The results, as a whole, support the notion that the effect of lexical distance on phonological awareness depends on modes of stimulus presentation.
\end{abstract}

Keywords: Arabic, diglossia, phonemic segmentation, phonemic deletion

\section{Introduction}

During the past decade, many researchers have become increasingly interested in reading processes and reading acquisition in the Arabic language. This interest has largely been motivated by the difficulties that native Arabic-speaking children face during reading acquisition, as attested by their relatively low achievements in international reading tests (Pirls, 2006). Researchers claimed that this low level of reading skills among the Arabic-speaking population is related to the uniqueness and the complexity of the orthography and to the rich and dense morphological and syntactic system, but it also seems to be related mainly to the challenging diglossic situation of this language. Arabic speakers are required to know both forms of the Arabic language: the spoken Arabic vernacular (SAV) and modern standard Arabic (MSA) (Saiegh-Haddad, 2003; Saiegh-Haddad \& Joshi, in press) or Literary Arabic.

Reading includes the ability to connect written symbols to meaningful words for the purpose of decoding a text. Despite the common understanding with regard to the different cognitive and linguistic components that underlie reading in different languages (Vellutino, Fletcher, \& Snowling, 2004), some researchers have claimed that the core component is related to the phonological processing skills (Stanovich, 1988), such as phonological awareness, i.e. the ability to think about the sound of a word rather than just the meaning. Phonological awareness may be evaluated through syllables, onsets and rhymes, and sounds. However, the awareness of the basic sounds (phonemic awareness) was found to be more difficult than the awareness of segments of syllables (Liberman, 1991; Goswami, Ziegler, \& Richardson, 2005). In addition, phonological awareness is considered to be a strong predictor of reading in different languages including Arabic (Elbeheri \& Everatt, 2007; Gillon, 2004; Shatil \& Share, 2003; Snowling, 2000; Taibah \& Haynes, 2010). 
These findings suggest that the level of phonological awareness during kindergarten constitutes a good measure to predict success in learning to read in early school grades (Share, Jorm, Maclean, \& Matthews, 1984). Children who start formal schooling without a strong phonological basis may find difficulties in internalizing the alphabetic principle especially if there is no clear and direct teaching of this principle. Moreover, it can be assumed that the fact that children are exposed to writing is not enough for a rapid and easy development of the phonological awareness needed to learn the rules of converting letters to phonemes.

In the context of the Arabic language, the study by Elbeheri and Everatt (2007) found a link between phonological awareness and reading skills among dyslexic Arab speakers. Significance differences were found between dyslexic children and the control group, differences that show low phonological abilities among dyslexic Arabic-speaking children. In the study by Abu-Rabia and Taha, (2006) on the Arabic language, it was also found that phonology is closely related to reading and spelling errors among native Arabic-speaking children from the first to the sixth grade (Abu-Rabia \& Taha, 2006). Similar results were also obtained by the study of Abu-Rabia, Share and Mansour (2003). This supports the observation that dyslexic Arab children have deficiencies in the area of phonological processing.

Despite the "quasi-consensus" in the field of reading research that phonological awareness is a core problem of dyslexic children (Share, 1995; Snowling, 2000), some researchers argue that phonological awareness is more critical in transparent orthographies where is the correspondence between grapheme and phonemes (GPC) are consistent, than in opaque orthographies where is the GPC is less consistent (Share, 2008; Seymour, Aro, \& Erskine, 2003). Other researchers claim that in transparent orthographies, such as vowelized Hebrew and Arabic, this aspect is weakened as the person grows up (Shatil \& Share, 2003; Taibah \& Haynes, 2010).

In fact, reading in transparent orthographies in which the consistency of the grapho-phonemic correspondence (GPC) allows children to develop rapidly decoding skills can enable accurate decoding as early as the end of the first grade (Landi, 2010). On the other hand, reading in opaque orthographies cannot rely on the GPC because the phonological information needed for the phonological recoding is not necessarily available. Hence, the process of reading in opaque orthographies may be more difficult and even slower than in transparent orthographies (Ziegler \& Goswami, 2005). Thus, here is a major importance in the linguistic characteristics and the depth of the orthography in determining the importance of phonological awareness in the language under discussion.

\subsection{The Arabic Language in the Diglossic Situation}

The Arabic language is characterized by diglossia meaning that there are two forms of the same language: (a) the spoken language and (b) the literary or standard language (Saiegh-Haddad \& Joshi, 2014). Readers use different forms in different situations (Ferguson, 1959). The child uses the spoken language for communication in his/her surroundings until the pre-school period, around the age of 5-6. Then a deliberate exposure to the standard language starts. The gap between the two forms is reflected at the phonological, morphological, semantic and syntactic levels (Saiegh-Haddad, 2003).

At the phonological level, spoken and literary Arabic are characterized through an overlapping, though not identical, phonemic range. In literary Arabic language, for example, there are some phonemes

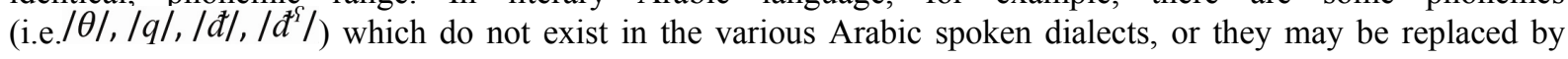
other phonemes that exist in some dialects; one example is the phoneme $/ \theta /$ in the word / $\theta$ ala: $\theta a /$ meaning three in the literary language changes to /tala:ti/in the spoken language, the phoneme $/ \theta /$ being replaced by $/ t /$.

Another phonological difference between the spoken and literary Arabic relates to the phonological structure of the syllables within the word. For example, while it is unacceptable for a literary Arabic word to start with consonant cluster, this phenomenon is acceptable and commonplace in the spoken language. For example, the cluster $/ 3 d /$ in the word $/ 3 d j: d /$, which means new. An additional difference in the phonological structure of syllables between the two languages is that one-syllable words with a consonant cluster are regarded as linguistically-correct and common in the literary language, though they are rare or even absent from the spoken language. For example the final cluster $/ \mathrm{lb} /$ in the standard word $/ \mathrm{kalb} /$, which means $d o g$ turn to $/ \mathrm{lib} /$ in the word $/ \mathrm{kalib} /$, in the spoken language. These changes occur due to the differences in the phonemic structure between the spoken and the standard language. Actually, there are phonological structures of the syllables that exist only in the standard language (CVCC); others exist only in the spoken language (CVCVC). However there are a few phonological structure that are common to both the spoken and the standard languages. 
The phonological difference between the spoken and the standard languages may exist in some dialects either at the level of phonemes or at the level of the phonological structure of syllables or words, meaning that the phonological distance between the two words becomes greater (Eviatar \& Ibrahim, 2001; Saiegh-Haddad, 2003).

At the lexical level, there are a number of items which are common to both languages on the one hand (i.e. /barj:d/), and there are items characterized by changeable levels of phonological distance between both languages on the other. The distance clearly deals with the existence of a number of phonemes only in the literary language and of changes in the phonological structure of syllables (i.e. CVCC vs CVCVC) in the two languages (Saiegh-Haddad, 2003). Similarly, there are some items with an insignificant phonological distance between the two languages, and there are some with a significant lexical distance. Moreover, there are lexical items which are completely different in the two languages (for example the literary word /muћat $t^{\S} t^{\S} \mathrm{am} /$, meaning crushed, becomes $/ m t^{\S} a b b a f /$ in the spoken language). It is worth noting that although both forms of the Arabic language are characterized by varying levels of similarity or distance, some researchers have argued that they are stored in separate lexicons (Ibrahim, 2008). In order to examine the relationship between the two forms of Arabic among adults, Ibrahim used lexical decision with auditory presentations and compared repetition effects within spoken Arabic and between languages (standard Arabic or Hebrew and spoken Arabic).

Saiegh-Haddad has conducted a series of studies on the Arabic language which examined the impact of the phonological and lexical gap between the spoken and literary language on the phonological performances of children, starting from kindergarten through fourth grade. It was found that the phonological manipulations conducted on linguistic components, existed in the literary language only are more difficult than those existed also in the spoken language (Saiegh-Haddad, 2003; 2004; 2007). The researcher attributes the difficulty to a deficiency in the phonological representation for words and sub-lexical units in the literary language. This may impede the construction of a quality phonological representation for literary words and even constrains the learning of newer words (Saiegh-Haddad, Levin, Hende, \& Ziv, 2011). The partially deficient phonological representation of literary structures may have an impact on reading and writing in the Arabic language.

Thus, the low phonological representation of sounds and linguistic structures existing only in the literary language may influence the process of writing and reading acquisition in the Arabic language.

\subsection{The Current Study}

The present study explores the effects of diglossia on the performance of specific language skills, (e.g. phonological awareness tasks). Our rationale was that if there is an advantage for the performance in the spoken language, it can be concluded that Arab-speaking children arrive at the stage of reading acquisition with immature phonological awareness which might delay reading and spelling acquisition in the early stages.

The hypothesis of this study is that not only does the performance depend on the phonological distance but also on the stimuli type (the spoken word vs. the literary word). Operationally, we investigate how similarities/differences in spoken and literary Arabic influence the performance of phonological awareness tasks.

Furthermore, we observe the cross-sectionally at different grades; this is very important, as we follow the children's growing acquisition of the literary language, and can, at the same time, examine the differences in the performance on phonological awareness tasks in both languages as a factor of literacy acquisition. Moreover, we intend to examine whether children at more advanced stages of a literary language can start to demonstrate better their phonological awareness tasks in an auditory modality (i.e. spoken Arabic).

Our main research question is about the way that diglossia impact the phonemic awareness in different grades, and whether the influence of diglossia decreases through grades. We expected that at early ages the phonemic awareness to the spoken word task will be better than that of the literary words and that and that the gap will vanish in higher grades.

\section{Method}

\subsection{Participants}

The participants were 571 children in grades 1 through 7, 9, 11 and 12. In each grade There were $50.5 \%$ boys. (see, Table 1). The sampling process was conducted in two stages: 10 different schools were recruited in the first stage by taking into account two important factors: the accent (divided into three populations as follows: Bedouin, Druze and Arabs); and the geographical factor (divided into four geographical regions): the South, Haifa, the center and the North. In places where there was more than one school, schools were coincidentally sampled. In the second stage, the examiner sampled each fifth child from the class register of the children. Children with physical, mental and learning disabilities and those with ADHD did not participate in this study. 
Table 1. Distribution of the participants across demographic characteristics $(\mathrm{N}=570)$

\begin{tabular}{ccccccccccc}
\hline Variables & \multicolumn{7}{c}{ Grades } \\
\cline { 2 - 10 } & 1 & 2 & 3 & 4 & 5 & 6 & 7 & 9 & 11 & 12 \\
\hline $\begin{array}{c}\text { Participant } \\
\#\end{array}$ & 59 & 60 & 53 & 59 & 60 & 60 & 54 & 54 & 57 & 54 \\
\hline Gender & & & & & & & & & & \\
Male & $61 \%$ & $61 \%$ & $56 \%$ & $58 \%$ & $55 \%$ & $48 \%$ & $62 \%$ & $42 \%$ & $27 \%$ & $54 \%$ \\
Female & $39 \%$ & $39 \%$ & $44 \%$ & $42 \%$ & $45 \%$ & $52 \%$ & $38 \%$ & $58 \%$ & $73 \%$ & $46 \%$ \\
\hline Population & & & & & & & & & & \\
Arab & $83 \%$ & $80 \%$ & $90 \%$ & $81 \%$ & $80 \%$ & $80 \%$ & $88 \%$ & $88 \%$ & $84 \%$ & $87 \%$ \\
Beduin & $7 \%$ & $10 \%$ & $0 \%$ & $8 \%$ & $10 \%$ & $10 \%$ & $0 \%$ & $10 \%$ & $9 \%$ & $2 \%$ \\
Druzy & $10 \%$ & $10 \%$ & $10 \%$ & $11 \%$ & $10 \%$ & $10 \%$ & $12 \%$ & $2 \%$ & $7 \%$ & $11 \%$ \\
\hline Area & & & & & & & & & & \\
North & $63 \%$ & $60 \%$ & $68 \%$ & $61 \%$ & $58 \%$ & $60 \%$ & $67 \%$ & $67 \%$ & $61 \%$ & $67 \%$ \\
Haifa & $10 \%$ & $10 \%$ & $11 \%$ & $10 \%$ & $12 \%$ & $10 \%$ & $11 \%$ & $11 \%$ & $11 \%$ & $11 \%$ \\
Centre & $20 \%$ & $20 \%$ & $21 \%$ & $20 \%$ & $20 \%$ & $20 \%$ & $22 \%$ & $22 \%$ & $19 \%$ & $20 \%$ \\
South & $7 \%$ & $10 \%$ & $0 \%$ & $9 \%$ & $10 \%$ & $10 \%$ & $0 \%$ & $0 \%$ & $8 \%$ & $2 \%$ \\
\hline
\end{tabular}

\subsection{Measures}

Two tasks were developed in order to examine phonological awareness: phonemic segmentation and phonemic deletion (see Appendix A and Appendix B). The items in this study were chosen following a pilot study which was conducted previously. Hence, the number of items in each task may be not entirely balanced. Furthermore, the majority of the items in one task varied considerably from those in the other task. A few items, however, were common in both tasks. This was to minimize the memory interference. Phonological awareness tasks were also previously developed in the Arabic language by several scholars including Abu-Rabia, 1995 and SaieghHaddad, 2003. These well-established tasks were employed for the specific versions used in this study.

Phonemic segmentation: The phonemic segmentation examined the ability to split words into phonemes. The task was created from a list of nineteen items divided into two categories (see Appendix A): there were ten words from the spoken language (reliability .80), 2) and nine words from the literary language (reliability .83). According to the extent of the frequency of items in the pilot conducted prior to the present study, items with average frequency were chosen, i.e., items which fall at 2.5-3.5 in a scale of 1-5 based on the evaluation of teachers. In addition items were composed of one-syllable words and two-syllable words. Thus the length of the word ranged from three phonemes in short words to seven phonemes in long words. The items were randomly organized in regard to their linguistic attribution (literary and spoken words). However, a permanent order was kept according the length of words (from the shorter to the longer). The phonological structure of the items included phonological structures that were common both in spoken and literary words (for example CVC) i.e., $/ \mathrm{damm} /$ meaning blood, and phonological structures that suited only the spoken language (CCVC) i.e., /ktab/ meaning book, and phonological structures that suited only the literary language (CVCC) i.e., /bint/ meaning girl. During a practice session, the subject heard the target word said by the researcher and after he/she had repeated it, the participant was asked to divide it into the phonemes from which the word was composed. Prior to the experiment, the subject received an explanation that in the list that he/she would hear were strange words or even meaningless ones (pseudo words). In this task, the researcher read the instructions before the practice session and was not allowed to intervene during the real experiment.

Phonemic deletion: This task examined the ability to perform deletion of phonemes at the begining, the middle and the end of the word (see Appendix B). The tasks consisted of a list of twenty items. The vast majority of these items were different from the phonemic segmentation task, which minimized the memory interference. However, a few items were common to both tasks. These items were divided, according to the pilot study, into two groups: nine words from the spoken language (reliability .79) and eleven words from the literary language (reliability .86). In this task, items were also subject to a frequency test similar to that in the first task; in the 
aftermath of the test, words with an average frequency were chosen. It is important to indicate that the phoneme on which the respondent was asked to participate was always a consonantal phoneme. The list was composed of one-syllable words and two-syllable words. Their length ranged from three sounds in short words to seven sounds in long words. The items were randomly organized based on their linguistic attribution (spoken and literary).

\subsection{Procedure}

Children were individually tested by an experimenter in a quiet room in one of the schools sampled in the study. The meeting lasted for an hour on average. The segmentation task preceded the deletion task due to the difficulty of the latter that we had noticed in a pilot study. For the purpose of carrying out this study, experimenters had received training in conducting and coding the tasks. All experimenters were holders of academic degrees from the Department of Education and the Department of Communication disorders.

\section{Results}

Table 2 presents descriptive statistics for the two phonological tasks arranged by type of words-spoken and literary — and by grades. In both tasks, children showed improvement through grades. However, this improvement is highlighted between the second and the third grades (between $10-15 \%$ in the different tasks). In addition, an opposite trend is manifested in the fourth grade, where the performance of children decreases in respect to the third grade.

Table 2. Performance ( $\%$ correct $)$ on the phonemic segmentation and the phonemic deletion tasks, across grades

\begin{tabular}{lllllllll}
\hline \multirow{2}{*}{ Grades } & \multicolumn{7}{c}{ Phonological tasks } \\
\cline { 2 - 8 } & \multicolumn{7}{c}{ Phonemic Segmentation } \\
\cline { 2 - 8 } & \multicolumn{7}{c}{ Spoken (10 items) } & \multicolumn{5}{c}{ Literary $(9$ items) } & Spoken (9 items) & Literary (11 items) \\
\cline { 2 - 8 } & M & SD & M & SD & M & SD & M & SD \\
\hline 1 & 51.9 & 28.5 & 41.1 & 28.2 & 34.7 & 24.0 & 42.5 & 26.7 \\
2 & 57.7 & 38.5 & 43.1 & 38.6 & 38.7 & 26.5 & 51.4 & 31.6 \\
3 & 67.0 & 23.4 & 55.5 & 24.6 & 59.4 & 23.1 & 76.4 & 22.3 \\
4 & 63.4 & 26.1 & 49.2 & 27.5 & 50.3 & 24.7 & 71.6 & 23.1 \\
5 & 69.4 & 28.1 & 59.5 & 30.6 & 57.8 & 24.5 & 75.3 & 26.2 \\
6 & 71.0 & 20.3 & 58.0 & 25.3 & 66.1 & 24.4 & 82.1 & 19.6 \\
7 & 74.7 & 20.1 & 61.5 & 24.1 & 65.0 & 25.3 & 80.1 & 23.8 \\
9 & 75.3 & 17.7 & 61.0 & 23.5 & 71.6 & 22.2 & 84.3 & 15.2 \\
11 & 75.3 & 22.6 & 61.2 & 27.4 & 71.0 & 26.0 & 83.1 & 20.8 \\
12 & 78.6 & 19.9 & 65.8 & 25.8 & 78.4 & 20.1 & 88.7 & 16.8 \\
Total & 68.2 & 26.5 & 55.4 & 29.0 & 58.8 & 27.6 & 73.2 & 27.2 \\
\hline
\end{tabular}

To answer our research question regarding the effects of the lexical distance - type of stimuli - and grade level on phonological awareness, two-way ANOVAs with repeated measures were conducted separately for each task. In each task the dependent variable was the percentage of accuracy and the independent variables were type of stimuli (words from the spoken vs. the literary language) and grade (ten levels).

\subsection{Phonemic Segmentation}

The results revealed a significant effect of the type of stimulus $F_{1,560}=324.1, \eta 2_{p}=.37, p<.001$. Overall, beyond grades, accuracy in phonemic segmentation of spoken words $(M=68.21, S D=26.52)$ was higher than that of literary words $(M=55.38, S D=28.97)$. A significant effect of grade was also found $F_{9,560}=6.31, \eta 2_{p}=.09$, $p<.001$. To examine the source for developmental differences between grades, post hoc comparisons using the Tukey HSD test were carried out. The performance of first grade children did not differ from second grade children but was significantly lower than Grades 3 through 12 . Second grade participants performed significantly 
lower in comparison to Grade 6 and above. In addition, the performance of the fourth graders was significantly lower than that of the tenth graders. No interaction between grade and type of word was found.

For a deeper analyses, derived from the differences in phonological structures that exist between the spoken and literary languages, statistical analyses were again carried out as similar phonological structures of items of spoken (eight items; $\alpha=0.79$ ) and literary words (six items; $\alpha=0.80$ ) were controlled (for example, CVC, $\mathrm{CV}-\mathrm{CV}, \mathrm{CV}-\mathrm{CVC}$ ). Yet the findings received in the in-depth tests were similar to those in the tests carried out where phonological structures were not controlled. Thus, a significant effect of type of stimuli $F_{1,560}=717.3, \eta 2_{p}$ $=.66, p<.001$ and of grade $F_{9,560}=5.59, \eta 2_{p}=.08, p<.001$ was observed. As with the preceding analysis, there was no interaction between the grade and the type of word. $F_{9,560}=0.28, \eta 2_{p}=.01, p>.05$.

\subsection{Phonemic Deletion}

The two-way ANOVA with repeated measures revealed a significant effect for the type of stimuli $F_{1,560}=450.19$, $\eta 2_{p}=.44, p<.001$. This indicated a significant difference in performance between omitting a sound from literary words omitting a sound from spoken words, beyond grades. The phonemic deletion in the literary words $(M=$ 73.20; $S D=27.16)$ was better than that in the spoken word $(M=58.84 ; S D=27.65)$. An effect for the grade was also found $F_{9,560}=24.41, \eta 2_{p}=.28, p<.001$ regardless of the type of stimuli. In addition, a significant interaction was found between stimuli type and grade $F_{9,560}=3.40, \eta 2_{p}=.05, p<.05$.

For the purpose of focusing on developmental trends, post hoc tests (Tukey) were carried out. No significant differences were found between the first and the second grade, but a significant difference was found between the first grade and all other grades $(\mathrm{p}<.05)$, between the third and the twelfth grade and between the fourth grade and the 11 th and the 12 th grades.

To confirm or to refute the surprising results received in the task of phonemic deletion, additional in-depth tests were carried out. These tests aimed at examining whether the opposite results received were influenced by differences in phonological structures of the items from the two groups, as well as differences between words with and without orthographical representation in the spoken/literary language.

The goal of the first in-depth analysis of the phonemic deletion task was to examine whether the source of differences regarding the results of this task is found in the various phonological structures of spoken words (six items; $\alpha=0.73$ ) and the literary words (eight items; $\alpha=0.76$ ) Obviously, there are phonological structures that exist only in the spoken language (for example, CVCVC), and other phonological structures that exist only in the literary language (for example, CVCC). Yet there are also phonological structures that are common to both languages (for example, $\mathrm{CVC}, \mathrm{CV}-\mathrm{CV}, \mathrm{CV}-\mathrm{CVC}$ ). It was decided therefore to conduct once more the performances in the task of phonemic deletion in the literary and spoken languages as phonological structure common to both groups were controlled. It is worth mentioning that as phonological structures were controlled, as was the length of the words. The results received were similar to those in the earlier comparison: a significant effect for the type of stimuli was found $F_{1,560}=514.77, \eta 2_{p}=.48, P<.001$. This indicated that an advantage was found for performance in literary language $(M=77.71, S D=27.23)$ over the spoken language $(M=58.75, S D=$ 27.99 , in which phonological structures were not controlled. In addition, a significant effect was found for grade $F_{9,560}=21.11, \eta 2_{p}=.25, P<.01$ and interaction between type and grade $F_{9,560}=3.26, \eta 2_{p}=.05, P<.01$.

The in-depth test regarding the phonemic deletion examined differences in the performance of spoken words without orthographical representation (nine items; $\alpha=0.79$ ) and literary words which have obviously orthographical representation (six items; $\alpha=0.76$ ). The results were similar to those of the general comparison, where orthographical representations were not controlled: a significant effect for the type of stimuli was found $F_{1,560}=260.05, \eta 2_{p}=.31, P<.01$. A higher ability was found for omitting phonemes from spoken and literary words with orthographical representation $(M=70.43, S D=28.44)$ compared to omitting phonemes from words in the spoken language without orthographical representation $(M=58.84, S D=27.65)$. In addition, a significant effect was found for grade $F_{9,560}=21.85, \eta 2_{p}=.26, P<.01$ and interaction between type and grade $F_{9,560}=2.38$, $\eta 2_{p}=.03, P<.05$.

Figure 1 illustrates the performance on the phonological segmentation and deletion tasks by type of words, beyond grade. 


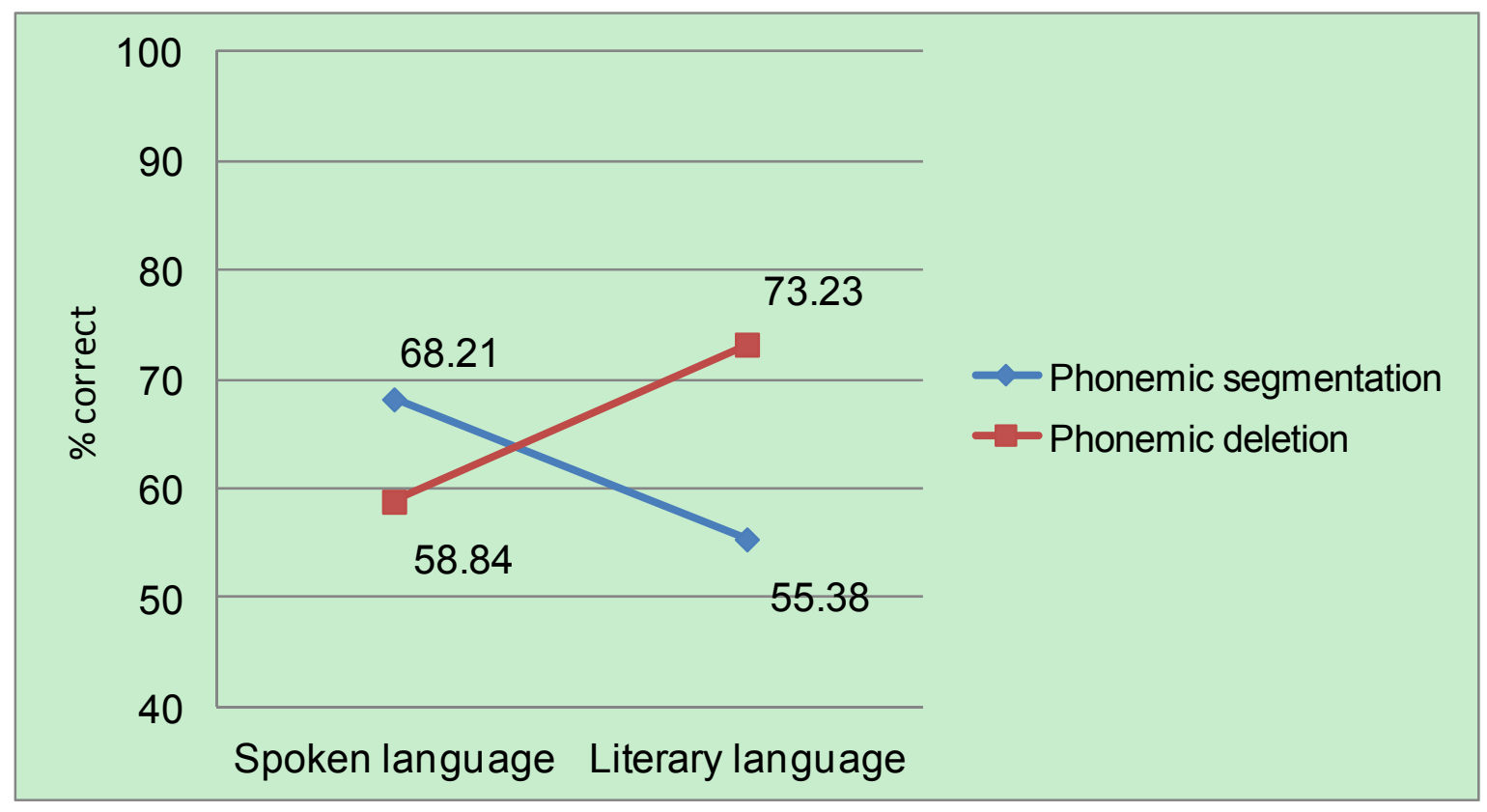

Figure 1. The performance on the phonological tasks in spoken and literary languages beyond grads

\section{Discussion}

The goal of the current study was to examine the impact of diglossia, a characteristic of the Arabic language, on the development of phonological abilities, critical to an intact development of reading ability among the population of Arab children. The impact of diglossia on the development of phonological awareness has been examined in the current study through measuring the phonological distance that exists between the spoken Arabic language and the literary Arabic language. A comparison was conducted for type of errors in both forms (literary and spoken) of the language, among various populations of speakers: speakers of different dialects. The result of the study pointed out the variance in the performance between the two tasks, developed to investigate the participants' phonological awareness on the one hand and, on the other, the significant differences in the participants' performance in the various grade levels regarding each task.

In the phonemic segmentation, as postulated, a significant advantage for performing spoken words was found over literary words. Yet, the post hoc analyses revealed that The performance of first grade children was significantly lower than all grades, except for the second grade, which in turn performed significantly lower in comparison to Grade 6 and above. In addition, the performance of the fourth graders was significantly lower than that of the tenth graders. This was also the case when phonological structures common to both groups were controlled.

This finding might be explained in the way in which the performances in the spoken language reflected more knowledge, experience, skill, maturity and consolidation of linguistic and meta-linguistic mechanisms of the spoken language in relations to the literary language. The results of the advantage in performing spoken words over literary words are consistent with the findings of Saiegh-Haddad (2003), where she has concluded that the advantage of the spoken language over the literary language in Arabic is manifested by stronger and more consolidated semantic links in the spoken language, a stronger control of phonemes and phonological and syllabic structures ascribed to the spoken language.

The findings received from the task of phonemic deletion which aimed at examining phonological awareness have shown the opposite trend in the participants' performances in relation to the earlier task of phonemic segmentation. In other words, performance in this task was better in the literary language than in the spoken language. These findings refute the current study's hypotheses.

To establish these findings, different analyses were conducted in which the phonological structures, number of items and place of omitted phoneme were controlled. These analyses showed that when performance in words from the spoken language without orthographical representations was compared with words from the spoken language that also exist in the literary language with orthographical representation, the latter resulted in better 
performances over the former. Eventually, it might be inferred that orthographical representation of words can explain the opposite results received for the task of phonemic deletion where there was an advantage for the literary language over the spoken one. Literature in this field indicates that in performing the task of phonemic deletion, there is a reliance on the visual mode, i.e., on orthographical patterns stored in the orthographical lexicon. Similar findings were reached in a study on the Persian language (Aaron et al., 1999), and in the study by Saiegh-Haddad (2004). The latter's study indicated that the performance of kindergarten and first grade children in the task of phonemic identification for literary words was lower than in spoken words (Saiegh-Haddad, 2004). The researcher explained her findings by stating that "orthographical representation of the literary language is unclear, this leads to automatic activation of the spoken language's dominant representations for literary structures" (p. 506). The current study's findings can be explained only through the connection to the auditory mode since the performance in the spoken language (with the dominant structures) is not good enough in comparison to the performance in literary words.

As is known, spoken words have no orthographical representation as literary words. Yet those are stored in a separate semantic lexicon (Bentin \& Ibrahim, 1996). Consequently, the accurate performance in spoken words was conducted in an analytical and focused manner based on analyses conducted through the auditory mode without the intervention of processes of withdrawal and memory as in literary words.

These results are consistent with the findings of Ibrahim (2008) that dealt with the perception of words (lexical decisions) in the speaking mode in comparison to perceiving literary Arabic and Hebrew. The question raised in his study asks whether the difference in the participants' performance is linked to the extent of exposure to the various modes in these languages. To this end, measures of reading time of answers and percentages of errors were compared in addition to a coordinating analysis between the variable of the extent of exposure to the language and the pace of performance in perceiving words in different modes. The results showed that children exposed to speaking in a literary language react more quickly to literary words than to words that presented through an auditory mode. Similar results received in the Hebrew language indicated that the performance of children whose exposure to the language in certain modes was higher: they could identify words in this specific mode more quickly and with greater accuracy.

Concerning the developmental process of the phonological awareness (from both phonological tasks), our findings provide evidence that the phonological awareness is a developmental capacity, which was reflected by a consistent improvement through grades. This improvement process, despite the fact that the significant differences were found mainly between the lower grades (firs-fourh) and the other grades, supports the view that the relation between literacy and phonological awareness is reciprocal (Ziegler \& Goswami, 2005). Ongoing through school, children are more exposed to written language, which seem to impact their phonological awareness. Of interest, however, is the "peak" that characterized this developmental process in the third grade, respect to other grades. It might be due to the direct exposure to the Hebrew and English languages' in this grade. This exposure helps to establish the principle of phonemic structure basically since these languages are characterized by shallow and deep orthography (respectively) (Bialystok, Martin, \& Majumder, 2003). Indeed, Eviatar and Ibrahim (2001), have concluded that an exposure to more than one language, increases the phonological awareness among speakers of a language. This suggests that, a good linguistic ability in the spoken language predicts a similar ability in the literary language.

An additional expected phenomenon in the development of phonological awareness is the decrease in the performance of fourth-grade students in relation to those in the third grade. A possible explanation for this phenomenon is that the transfer from vowelized reading to unvowelized reading takes place in the fourth grade. This may explain the phonological superiority of third-grade students who read the "shallow" vowelized Arabic language over fourth-grade students who have to deal with the increasing orthographical depth. This process could confuse the reader and even weaken the meta-linguistic ability for a certain period of time. These abilities tend to be recovered gradually with the increase of the level of exposure. In addition, there are results in the nominal Hebrew language indicating the lack of linearity in a part of the phonological development manifested in vowelized reading (Ravid, 2005; Shany, Bar-On \& Katzir, 2011).

\section{Conclusions}

The current study emphasizes the dissociation between the two tasks on phonemic awareness. While the performance of the spoken word was better than the literary word in the phonemic segmentation, the performance of literary words was better than that of spoken words in the phonemic deletion. These differences between the two tasks may suggest that these tasks are processed differentially, i.e. the phonemic segmentation seems to be elaborated via the auditory modality, while the phonemic segmentation is elaborated more via the 
visual modality. In addition, our finding providing evidence concerns the developmental capacity of phonemic awareness (Rosenhouse, 2000), suggesting a reciprocal relation with literacy. It should be noted that these results have direct implications on the policy of the school according to which the literary Arabic language should serve in speaking situations inside schools for the purpose of internalizing it among the children. As a result of the data collected in recent years regarding the level of reading in the country, data that indicated a low level of achievement among native Arab children in comparison to speakers of other languages, it is very important to create and to develop an awareness among parents and teachers toward developing a teaching system to implement these recommendations.

Finally this study sheds light on the various standardized measures that have already been developed and will be developed in the future to examine the phonological abilities of native Arab speakers with a focus on the differences between the oral and written languages.

\section{References}

Aaron, P. G. A., Joshi, R. M., Ayotollah, M., Ellsberry, A., Henderson, J., \& Lindsey, K. (1999). Decoding and sight-word naming: Are they independent components of word recognition skill? Reading and Writing, 11, 89-127. http://dx.doi.org/10.1023/A:1008088618970

Abu-Rabia, S. (1995). Learning to read in Arabic: Reading, syntactic, orthographic and working memory skills in normally achieving and poor Arabic readers. Reading Psychology: An International Quarterly, 16, 351-394. http://dx.doi.org/10.1080/0270271950160401

Abu-Rabia, S., Share, D., \& Mansour, M. (2003). Word recognition and basic cognitive processing among reading disabled and normal readers in Arabic. Reading and Writing: An Interdisciplinary Journal, 16, 423-442. http://dx.doi.org/10.1023/A:1024237415143

Abu-Rabia, S., \& Taha, H. (2006). Phonological errors predominate in Arabic spelling across grades 1-9. Journal of Psycholinguistic Research, 35, 167-188. http://dx.doi.org/10.1007/s10936-005-9010-7

Allaith, Z. A., \& Joshi, R. M. (2011). Spelling performance of English consonants among students whose first language is Arabic. Reading and Writing, 24(9), 1089-1110. http://dx.doi.org/10.1007/s11145-010-9294-3

Bentin, S., \& Ibrahim, R. (1996). New evidence for phonological processing during visual word recognition: The case of Arabic. Journal of Experimental Psychology: Learning, Memory, and Cognition, 22, 309-323. http://dx.doi.org/10.1037/0278-7393.22.2.309

Bialystok, E., Martin, M., \& Majumder, S. (2003). Phonological awareness: Is there a bilingual advantage developing? Applied Psycholinguistic, 24, 27-44. http://dx.doi.org/10.1017/S014271640300002X

Elbeheri, G., \& Everatt, J. (2007). Literacy ability and phonological processing skills amongst dyslexic and nondyslexic speakers of Arabic. Reading and Writing, 20, 273-294. http://dx.doi.org/10.1007/s11145-006-9031-0

Eviatar, Z., \& Ibrahim, R. (2001). Bilingual is as bilingual does: Meta-linguistic abilities of Arabic-speaking children. Applied Psycholinguistics, 21, 451-471. http://dx.doi.org/10.1017/S0142716400004021

Ferguson, C. A. (1959). Diglossia. In P. P. Giglioli (Ed.), Languages and Social Context (pp. 232-251).

Gillon, G. T. (2004). Phonological awareness: From research to practice. New York, NY: The Guilford Press.

Goswami, U., Ziegler, J. C., \& Richardson, U. (2005). The effects of spelling consistency on phonological awareness: A comparison of English and German. Journal of Experimental Child Psychology, 92(4), 345-365. http://dx.doi.org/10.1016/j.jecp.2005.06.002

Ibrahim, R. (2008). Does visual and auditory word identification have a language-selective input?: Evidence from word processing in Semitic languages. The Linguistics Journal, 3(2), 82-102.

Landi, N. (2010). An examination of the relationship between reading comprehension, higher-level and lower-level reading sub-skills in adults. Reading and Writing, 23(6), 701-717. http://dx.doi.org/10.1007/s11145-009-9180-z

Liberman, I. Y. (1991). Phonology and beginning reading: A tutorial. Hillsdale, N.J. England: Lawrence Erlbaum association.

Perfetti, C. A., Beck, I., Bell, L. C., \& Hughes, C. (1987). Phonemic knowledge and learning to read are reciprocal: A longi-tudinal study of first grade children. Merrill-Palmer Quarterly, 33(3), 283-319. 
Ravid, D. (2005). Hebrew orthography and literacy. In R. M. Joshi, \& P. G. Aaron (Eds.), Handbook of Orthography and Literacy (pp. 339-363). Mahwah, NJ: Erlbaum.

Rosenhouse, Y. (2000). The acquisition of Arabic as mother tongue (mainly in Israel). Oriento Moderno, 19, 119-151.

Saiegh-Haddad, E. (2003). Linguistic distance and initial reading acquisition: The case of Arabic diglossia. Applied Psycholinguistics, 24, 115-135. http://dx.doi.org/10.1017/S0142716403000225

Saiegh-Haddad, E. (2007). linguistic constraints children's ability to isolate phonemes in diglossic Arabic. Applied Psycholinguistics, 28(4), 607-625. http://dx.doi.org/10.1017/S0142716407070336

Saiegh-Haddad, E. (2004). The impact of phonemic and lexical distance on the phonological analysis of words and pseudowords in a diglossic context. Applied Psycholinguistics, 25, 495-512. http://dx.doi.org/10.1017/S0142716404001249

Saiegh-Haddad, E., Levin, I., Hende, N., \& Ziv, M. (2011). The Linguistic Affiliation Constraint and phoneme recognition in diglossic Arabic. Journal of Child Language, 38(2), 279-315. http://dx.doi.org/10.1017/S0305000909990365

Saiegh-Haddad, E., \& Joshi. M. (2014). Handbook of Arabic Literacy. Dordrecht, Heidelberg. London, New York.

Seymour, P. H. K., Aro, M., \& Erskine, J. M. (2003). Foundation literacy skills in European orthographies. British Journal of Psychology, 94, 143-174. http://dx.doi.org/10.1348/000712603321661859

Shany, M., Bar-On, A., \& Katzir, T. (2011). Reading different orthographic structures in the shallow-pointed Hebrew script: A cross-grade study in elementary school (pp. 1-22). Reading and Writing.

Shatil, E., \& Share, D. L. (2003). Cognitive antecedents of early reading ability: A test of the modularity hypothesis. Journal of Experimental Child Psychology, 86(1), 1-31. http://dx.doi.org/10.1016/S0022-0965(03)00106-1

Share, D. L. (1995). Phonological recoding and self-teaching: Sine qua non of reading acquisition. Cognition, 55, 151-218. http://dx.doi.org/10.1016/0010-0277(94)00645-2

Share, D. L. (2008). On the Anglocentricities of current reading research and practice: The perils of overreliance on an "outlier" orthography. Psychological Bulletin, 134(4), 584-615. http://dx.doi.org/10.1037/0033-2909.134.4.584

Share, D. L., Jorm, A. F., Maclean, R., \& Matthews, R. (1984). Sources of individual differences in reading $\begin{array}{lllll}\text { achievements. Journal of Educational Psychology, } & 76, & \text { 1309-1324. }\end{array}$ http://dx.doi.org/10.1037/0022-0663.76.6.1309

Snowling, M. (2000). Dyslexia (2nd ed.). Oxford: Blackwell.

Stanovich, K. E. (1988). Explaining the difference between the dyslexic and the garden variety poor reader: The phonological-core variable-difference model. Journal of Learning Disabilities, 21(10), 590-612. http://dx.doi.org/10.1177/002221948802101003

Taibah, N. J., \& Haynes, C. W. (2010). Contributions of phonological processing skills to reading skills in Arabic-speaking children. Reading and Writing: An Interdisciplinary Journal.

Vellutino, F. R., Fletcher, J. M., \& Snowling, M. J. (2004). Specific reading disability (dyslexia): What have we learned in the past four decades? Journal of Child Psychology and Psychiatry, 45, 2-40. http://dx.doi.org/10.1046/j.0021-9630.2003.00305.x

Ziegler, J. C., \& Goswami, U. (2005). Reading acquisition, developmental dyslexia, and skilled reading across languages: A psycholinguistic grain size theory. Psychological Bulletin, 131(1), 3-29. http://dx.doi.org/10.1037/0033-2909.131.1.3 


\section{Appendix A}

Phonemic segmentation items: Spoken and Literary

\begin{tabular}{|c|c|c|c|}
\hline & Spoken & & literary \\
\hline باص & $\mathrm{ba}: \mathrm{s}^{\mathrm{S}}$ & $y$ & la: \\
\hline رُز & ruz & ظِل & $\partial^{\S}$ el \\
\hline بيت & bet & ظَكَرْ & $\partial^{\varsigma} \mathrm{ahr}$ \\
\hline مُر مر & mur & طلى & $t^{f}$ ald: \\
\hline زوم & ZW:m & شَمْس & fams \\
\hline سَما & sama: & سَتَّه & salla \\
\hline تُرَاب & tra:b & قَلَم & qalam \\
\hline دِلِع & diles & جَرَس & $3^{\text {aras }}$ \\
\hline بَذِِر & bizer & دففتر & daftar \\
\hline هَزْتوت & maztw:t & & \\
\hline
\end{tabular}

\section{Appendix B}

Phonemic deletion items: Spoken and Literary

\begin{tabular}{|c|c|c|c|c|c|}
\hline \multicolumn{2}{|c|}{ Spoken } & \multirow{2}{*}{$\begin{array}{l}\text { deletion } \\
\mathrm{z}\end{array}$} & \multicolumn{2}{|c|}{ literary } & \multirow{2}{*}{$\begin{array}{l}\text { deletion } \\
\mathrm{m}\end{array}$} \\
\hline رُز & ruz & & مَريض & marj: $d^{\text {q }}$ & \\
\hline سِكِينه & sikkj:ni & $\mathrm{s}$ & تَنَعَلَب & $\theta a$ Slab & $\theta$ \\
\hline دُبَّانهِ & dubba:ni & $\mathrm{b}$ & عَمْ & Sam & q \\
\hline جَوَافَة & gauwa:fa & $\mathrm{g}$ & ظظل & $\chi^{\complement}$ ell & $\partial^{i}$ \\
\hline باص & $\mathrm{ba}: \mathrm{s}^{\mathrm{q}}$ & $s^{q}$ & بَريد & barj:d & $d$ \\
\hline دِلع & dilef & i & تُفاح & tuffa:h & $\mathrm{t}$ \\
\hline مطَبَش & $\mathrm{mt}^{\mathrm{f}} \mathrm{abba} \int$ & $\int$ & شَجَرَه & Sazara & $\int$ \\
\hline بزِر & bizer & $\mathrm{b}$ & ضِد & $d^{\S} e d$ & $d^{\S}$ \\
\hline \multirow[t]{3}{*}{ بايخٍ } & ba:je $\chi$ & $\chi$ & مقِنديل & qindj:1 & $q$ \\
\hline & & & حَليب & halj:b & $\mathrm{b}$ \\
\hline & & & مَسنطرَرَه & $\operatorname{mast}^{\mathrm{g}}$ ara & $t^{\mathrm{S}}$ \\
\hline
\end{tabular}

\section{Copyrights}

Copyright for this article is retained by the author(s), with first publication rights granted to the journal.

This is an open-access article distributed under the terms and conditions of the Creative Commons Attribution license (http://creativecommons.org/licenses/by/3.0/). 